\title{
Improving traffic management through the use of intelligent transport systems
}

\author{
Alina Kambur ${ }^{*}$, Liliya Kushchenko $^{2}$, and Ivan Novikov ${ }^{3}$ \\ ${ }^{1}$ Belgorod State Technological University named after V.G. Shukhova, Russia
}

\begin{abstract}
The high degree of the trend in the development of the car park leads to significant problems: an increase in road accidents; reduced bandwidth, especially during peak hours; overrun and loss of time by road users; overconsumption of fuel and, as a result, deterioration of the environmental situation. One of the ways to solve the problem of traffic management is the use of intelligent transport systems (ITS). Examples of the use of ITS in various countries are given, improvements in the use of systems are considered. The system "Auto-Intellect" used on the territory of the Russian Federation is considered. On the example of the city of Belgorod, a method is proposed for using ITS by prohibiting vehicles from entering the city, taking into account certain state license plates.
\end{abstract}

The high degree of the trend in the development of the car park leads to significant problems: an increase in road accidents; reduced bandwidth, especially during peak hours; overrun and loss of time by road users; excessive fuel consumption and, as a result, environmental degradation.

Domestic and foreign scientists are engaged in solving the problem of organizing traffic. From foreign I will single out the following works: "Development of electronic stability control of the car, safety technology designed to increase stability and control of the car in all driving situations" - by Jennifer Dang; "Development of the technology of foundation brakes and modern brake control systems" - the authors are Sebastian Silvani and Douglas Skorubsky; "Numerical Methods for Scientists and Engineers" R. V. Hamming. Among the domestic works of V. V. Klyuev, P. Parkhomenko "The use of computers in production"; B. M. Kagan "Electronic computers and systems"; Shibanova G. P. "Recognition in systems of auto control" and others.

Taking into account the stochastic nature of road traffic, the dynamism of changes in characteristics over time, a high-quality assessment and forecasting of changes in road traffic situations on the road network is a great difficulty [1].

To apply various methods of traffic management, it is necessary to collect data on traffic intensity, flow rate, and congestion in real time [2]. The use of intelligent transport systems can improve traffic management in various ways.

ITS is a system integration of modern information and communication technologies and automation equipment with transport infrastructure, vehicles and users, focused on

*Corresponding author: bobeshko.alya@mail.ru 
improving the safety and efficiency of the transport process, comfort for drivers and transport users [3].

The scope of ITS application in the country and around the world ranges from solving problems of public passenger transport, improving road safety, minimizing congestion, increasing the productivity of the intermodal transport system (including road, rail, air and water transport) to environmental and energy problems [4].

Basic technologies of the vehicle and transport infrastructure allow [5-7]:

- Manage traffic on highways and autobahns;

- Perform commercial road freight transport;

- Prevent collisions of vehicles and increase the safety of their movement;

- Produce electronic payment systems for transport services;

- Drive vehicles in emergency situations;

- Manage traffic on the main road network;

- Manage the elimination of the consequences of road accidents;

- Inform road users;

- Carry out weather control on the roads;

- Drive public passenger transport.

In Italy, as part of the development of ITS, a system of automated monitoring of vehicle movement and control of their movement has been deployed [8]. This system covers approximately $6,000 \mathrm{~km}$ of the toll road, as well as the main national highway. The traffic monitoring system in Italy is integrated with the Telepass system, which provides an electronic toll collection system.

France is one of the European leaders in the field of ITS implementation [9]. Northern France has an integrated system of automatic monitoring and control of vehicle traffic on the roads, including toll ones, connecting Paris, Lille, Rouen and Rennes. The organizational basis of the system is a public-private partnership between the French government, departmental governments and two private operators of the toll road system SAPN and SANEF. To inform drivers about traffic conditions on the most congested sections of high-speed roads, for example, in the gravitational zone of Paris, panels with variable information are widely used, which display information about the predicted travel time to the nearest settlements.

$\mathrm{n}$ the Czech Republic, a vehicle dynamic weighing system (Weigh-in-motion, WiM) is used, which allows detecting overloaded vehicles in order to protect the existing road network from damage and collect statistical data on transport using Czech roads [10]. The checkweighing system consists of an evaluation unit, a classifier in a switchboard located next to the road, and corresponding piezoelectric elements and inductive loops in each lane. It also includes video cameras for identification of registration numbers with infrared illumination. The information received by the system is transmitted to the re-weighing points via mobile networks or a traffic information system. There are currently 10 weighing stations in operation on the Czech road network.

In Germany, highway management systems are installed on 3,200 $\mathrm{km}$ of the federal road network. On the example of the A9 Autobahn the following conclusions:

- Reduction of material losses incurred in road accidents;

- Reduction of time costs (travel time and downtime);

- Decrease in operating costs [11];

- Reduction of exhaust gas emissions;

- Decrease in the number of road accidents by $35.9 \%$;

- Decrease in the number of road accidents involving victims by $34.4 \%$;

- Decrease in the number of victims of road accidents by $31.0 \%$.

Traffic management is provided by variable information signs, mainly regulating the speed of movement, and variable information boards (traffic information boards), 
recommending, among other things, optimal traffic routes. Multi-position signs are also used to regulate traffic in lanes and at motorway entrances [12].

In Finland, weather monitoring is widely used on the roads. The first automatic Vaisala road stations were installed in 1977 [13]. There are about 400 road weather stations and 300 weather cameras in Finland. Road weather stations are used to monitor the condition of the road surface, air temperature and road surface. Road weather cameras are used to visually monitor road and weather conditions. The systems constantly inform drivers about the traffic situation in the city by transmitting messages by radio in the AM or FM band.

On the territory of South Korea, the city-wide traffic management system TOPIS has been introduced, which allows detecting congestion caused by accidents and construction works, monitors traffic conditions on 450 roads and 3000 intersections in real time, using more than 700 video surveillance cameras installed throughout the city. The TOPIS system also integrates toll cards (T-cards), automatic regulation systems, a radio broadcasting system for transport, and the police service into a single administrative center [14]. Thus, through a single center, information on the operation of 8,000 buses in Seoul is processed in real time, providing data on each bus and each route. This functionality is achieved through the use of GPS and wireless connectivity.

In Hong Kong, a unified traffic light control system has been applied, in which the wires located under the road surface determine the number of cars, thereby the green traffic light cycle prevails in the direction where the number of vehicles is greater. Thus, a "green wave" is created at this and subsequent intersections [15].

In Singapore's congestion management system, Electronic Road Pricing (ERP) is coming to the fore. Since 1975, special arches have been installed in the business center of Singapore, the passage through which was initially carried out only under licenses. Now this process is fully automated: when driving through such an ERP arch, a certain amount is withdrawn from the cash card (In-Vehicle Unit - IU) - they are equipped with almost all cars) of the car owner. The introduction of ERP allows to reduce traffic during peak hours by 25,000 vehicles and increase the average speed by 20 kilometers per hour, the economic effect is $\$ 40$ million.

A GPS-based automatic vehicle location (AVL) system has been introduced in London, which makes it possible to manage the bus fleet, inform passengers in real time and provide priority passage for buses through traffic lights. The iBus system covers 3,200 traffic lights and 8,000 buses.

London, Paris, Seoul and other cities around the world have begun to develop car-free policies to reduce carbon dioxide emissions and expand walkways. Some regulations provide for low emission zones or a ban on diesel transport, which is a source of air pollution, instead of using public passenger transport and electric transport, metro and bicycles.

Other cities have introduced a pricing system - drivers are charged for travel during peak hours, in crowded urban areas, or for vehicles that violate emission standards.

Another way is to restrict the movement of cars with certain signs: on some days it is forbidden to drive cars with even numbers, on others - with odd numbers. The odd / even number ban system is widespread in central London and Paris, and since December 2016 in the Greek capital.

In the Russian Federation, Auto-Intellect is used - a solution for intelligent traffic control and license plate recognition. The system is based on three intelligent modules:

- license plate recognition module;

- module for determining the characteristics of traffic flows;

- "Radar" module. 
"Auto-Intellect" allows collecting statistics on traffic flows, helps traffic police officers detect traffic violations, determine the presence of congestion, it is possible to use it together with an access control system for automated control of vehicle travel.

The license plate recognition module automatically detects and recognizes license plates in the field of view of the camera. It allows you to record and record in the SQL database the recognized number, as well as the TM image, part of the frame with the license plate and the time of registration. Thus, a database of all cars that have passed through the control zone is formed by adding a text comment to each recognized license plate. Together with the "Radar" module, a module for the recognition of license plates and registration of traffic police numbers for migrants at a speed limit. It is possible to compare the recognized numbers with a third-party database of numbers (for example, cars listed in theft), which allows the module to be used for tracing purposes. Another important application of the module is its use in systems of automatic accounting and control of vehicle access to guarded objects and paid parking lots.

The module allows you to recognize 288 types of state registration plates containing numbers, Cyrillic or Latin letters.

The module for monitoring the characteristics of traffic flows can be used as part of the Auto-Intellect complex solution for intelligent traffic monitoring and license plate recognition. This technique will consist in restricting entry into the city on weekdays during peak hours according to the following principle: for numbers ending in:

- 1-2, no entry on Mondays;

- 3-4, no entry on Tuesdays;

- 5-6, no entry on Wednesdays;

- 7-8, no entry on Thursdays;

- 9-0, no entry on Fridays.

1000 meters before entering the city, the information board will duplicate the data on the ban on entry (Fig. 1) so that drivers can react in time. For example, take advantage of the "intercepting" parking lot and continue on public transport.

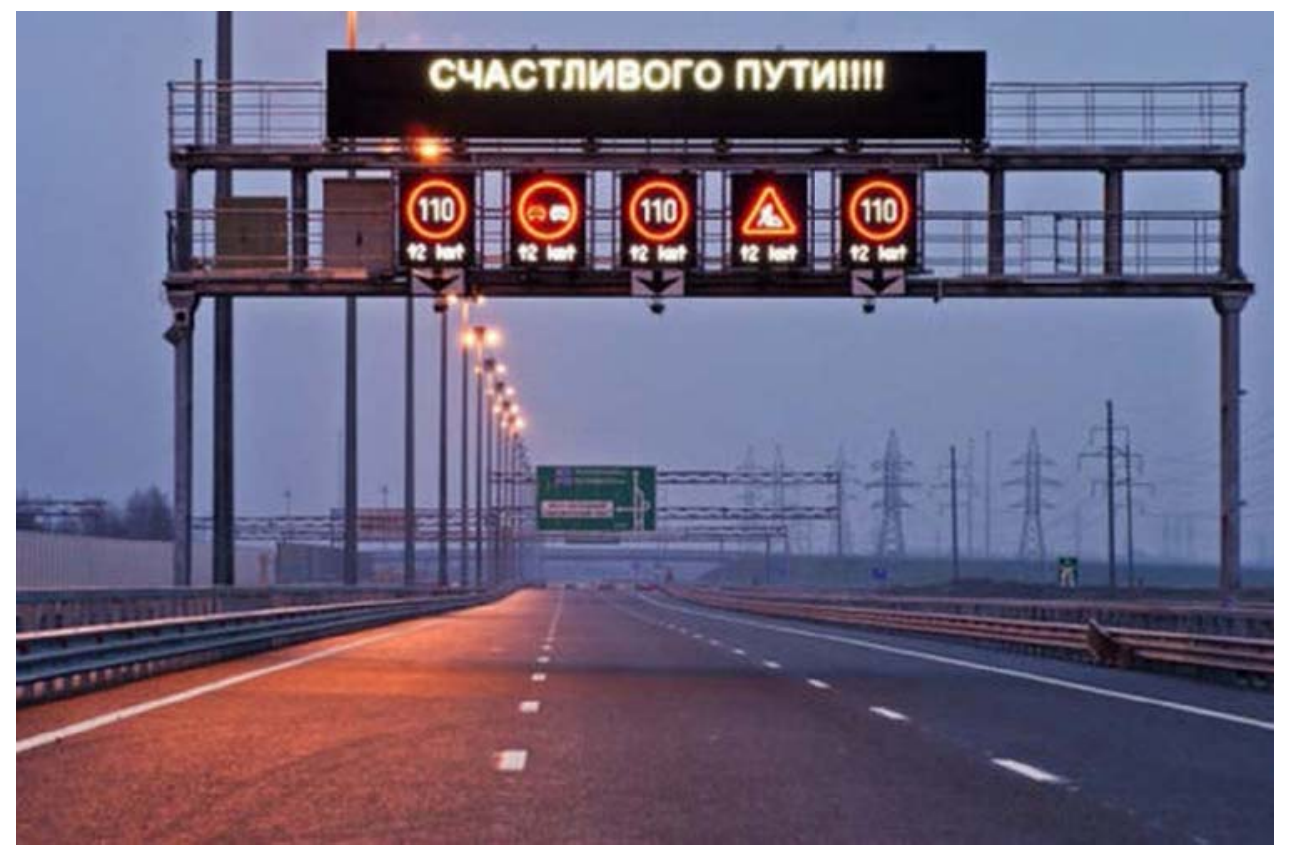

Fig. 1. Information boards 
Route schedule, travel time, geolocation of public transport are displayed on a board at each stop complex for the convenience of passengers.

Pre-trip information and information at stops have shown that they have a significant impact on the behavior of most passengers. It turned out that they ultimately caused a small but noticeable increase in the number of passengers.

For example, in Turin, the integration of urban transport management, public transport services and information systems has resulted in a $14 \%$ reduction in public transport travel times and $17 \%$ in passenger cars. This resulted in a 3\% increase in public transport and an overall improvement in road traffic in the city.

To control transport, an intelligent video surveillance system is used, which allows you to read numbers, identify offenders, transfer their data to the traffic police to receive a fine.

With the help of field studies, an analysis was carried out of the entrance to the city of Belgorod in the direction No. 1 Shopino-Belgorod from May 01, 2020 to December 31, 2020 (Fig. 2).

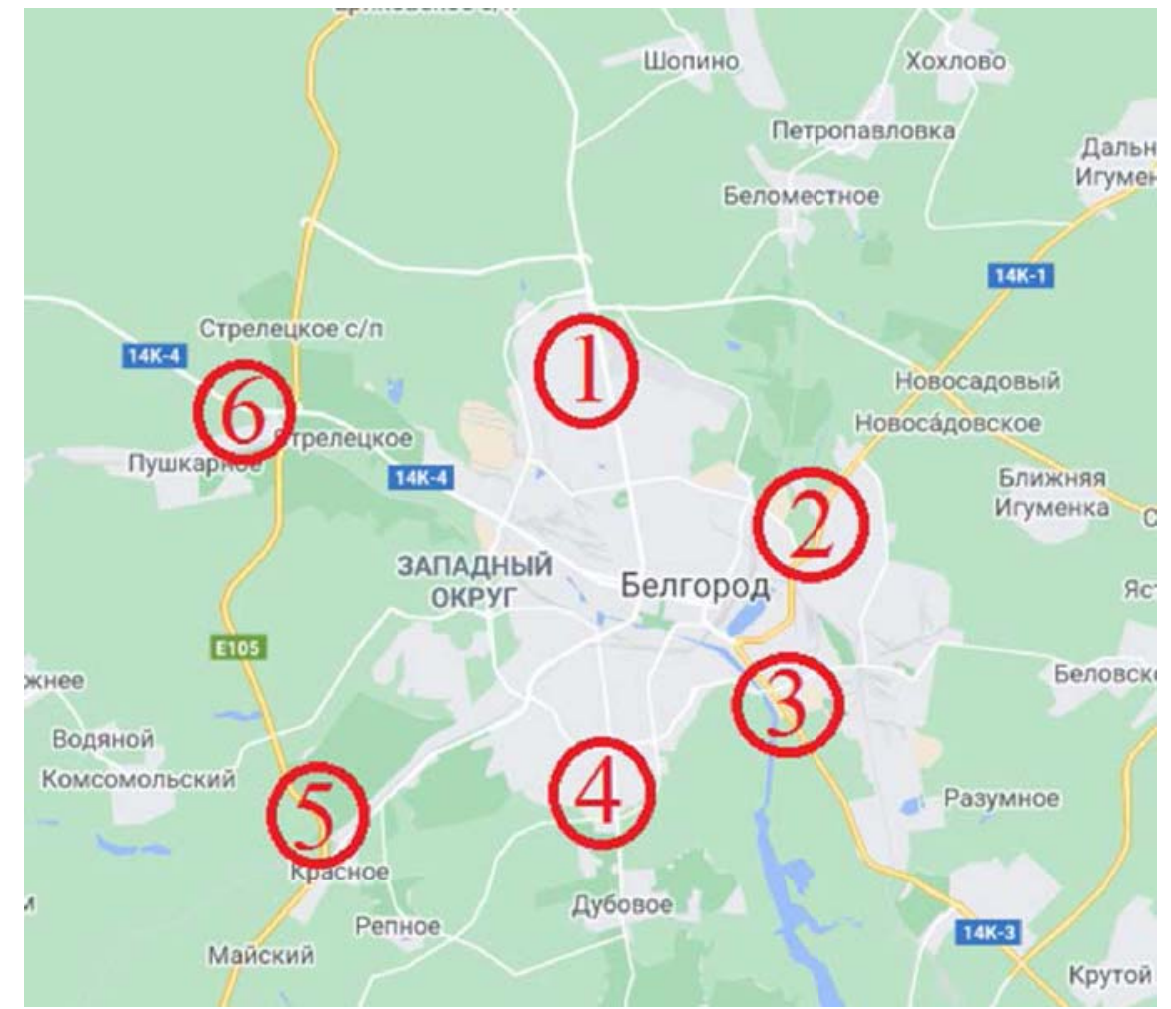

Fig. 2. Directions of entrances to the city of Belgorod

The peak hours in this direction from 08:00 to 09:00 were identified, the traffic intensity is 2287 cars/hour; from 13:00 to $14: 00$ - 1811 cars/hour; from 17:00 to 18:00 - 1963 cars/hour.

An experiment using this technique allows to reduce the number of congestions by $22 \%$, improve the environmental situation by $25 \%$, and achieve an economic effect of fuel consumption by $18 \%$. In fig. 3 demonstrates a comparative analysis of the application of the method, which shows the quantitative difference between cars that can enter the city. 


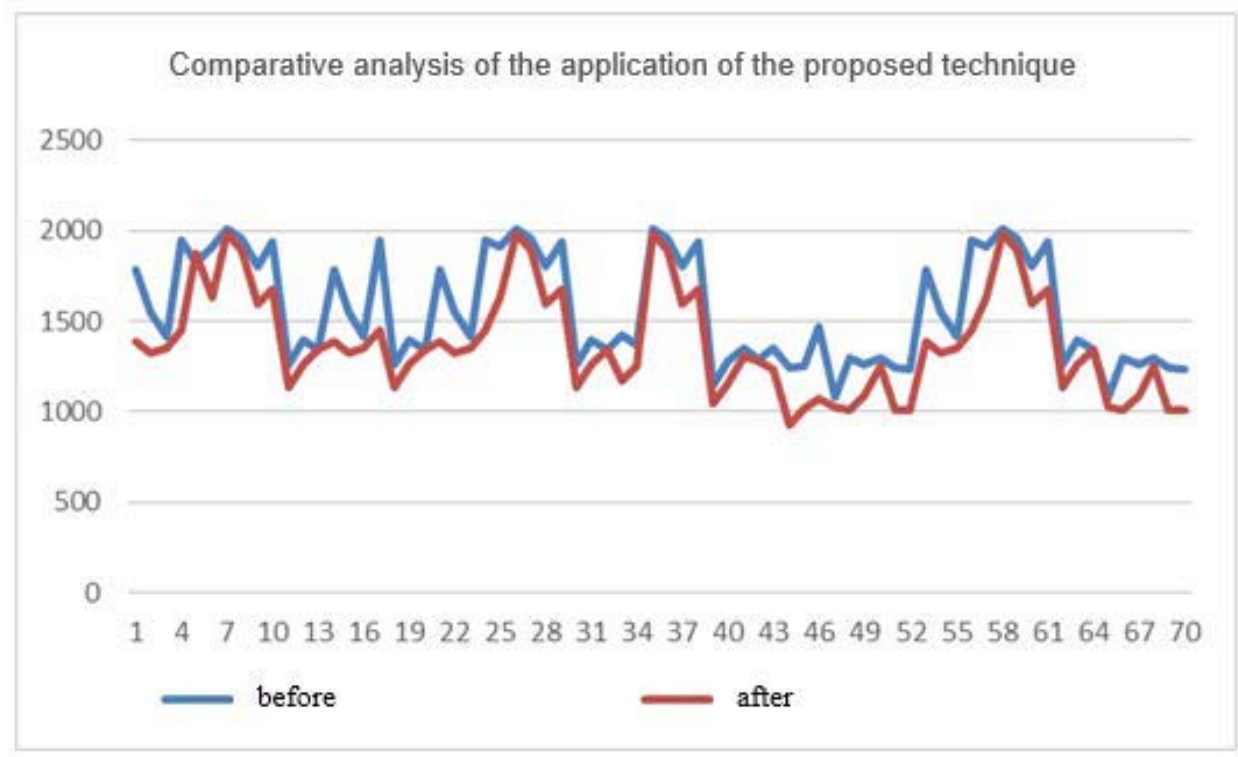

Fig. 3. Comparative analysis of the application of the proposed technique

Russian ITS allows you to provide:

1. Informing drivers about their violation of traffic rules and car operation, as well as about long-term and short-term forecast about the state of road traffic conditions.

2. Automatic recording of traffic violations to identify and punish those responsible.

3. Increasing the attention of drivers when driving in various stressful driving conditions.

4. Reducing the travel time of passengers by all land modes of urban transport, which is currently very important.

5. Increasing the capacity of city streets and roads by regulating traffic flows and generating warning information about traffic conditions.

6. Ensuring the passenger can choose the optimal route for public transport from the starting point to the end point, taking into account routes, timetables of public transport routes, as well as in the traffic situation and traffic density.

7. Optimization of routes of movement of vehicles, taking into account the relevance of the state of road traffic and the dynamics of changes in traffic congestion.

This technique is effective both for reducing congestion, increasing the throughput network, but also for increasing the demand for public transport, which corresponds to the setting of the strategy for the development of road transport and urban land electric transport in the Russian Federation for the period up to 2030.

\section{References}

1. Vasiliev A.P. Operation of highways. In 2 volumes: a textbook for students. higher studies. institutions / A.P. Vasiliev. - M .: Publishing Center "Academy", p. 320 (2010)

2. Hooker J. Optimal driving for single vehicle fuel economy. Transportation Research, vol. 22A, p.p. 183-201, (1988) 
3. Vlasov V.M. Intelligent transport systems in the automobile and road complex / V.M. Vlasov, V.M. Prikhodko, S.V. Zhankaziev, A.M. Ivanov. M .: MADI. - M .: OOO "MAILER" p. 487(2011)

4. Gay L.E. Congestion phenomena. Warning possibilities [Text] / L.Ye. Guy, A.I. Shutov, P.A., Volya, S.V. Kushchenko // Bulletin of BSTU im. V.G. Shukhov. - 2013. - No. 3.

5. Zhankaziev S.V. Intelligent transport systems: textbook. allowance / S.V. Zhankaziev. - M .: MADI, p. 14 (2016)

6. Zyryanov V.V., Kocherga V.G., Pozdnyakov M.N. Modern approaches to the development of integrated traffic management schemes // Transport of the Russian Federation. SPb. - No. 1. - p. 28-33 (2011)

7. Novikov, I.A. Technical means of traffic organization [Text]: educational-methodical complex / I.A. Novikov. - Belgorod: BSTU im. V.G.Shukhova,- p. 302 (2009)

8. Fenzi A., Bolelli A., Sacca G. INFOTEN Italia. Multimodal passenger information services. "Traffic technology international". Feb/Mar., p.p. 47-51, (1998)

9. Daniel T., Lepers B. Automatic incident detection: a key tool for intelligent traffic management. "Traffic technology international". Annual Review. 1996, p.p. 158-162.

10. Ezell S. Intelligent Transportation Systems. - Washington, D.C.: ITIF, p. 21 (2010)

11. Jaffe R.S. The US National ITS Architecture. Part 2 Application. "Traffic technology international". Aug/Sept, p.p. 71-75, (1996)

12. Larson R., Korsak A. A dynamic programming successive technique with convergence proofs. Automatica, vol. 6, p.p. 245-260, (1970)

13. Kulmala R., Noukka M. Raiting the objectives. Finland's ITS strategy to 2010. "Traffic technology international". Feb/Mar., p.p. 62-66, (1998)

14. Reynolds S. Architectural TRENDS. A real time distributed database for Europe. "Traffic technology international". Feb/Mar., p.p. 37-39, (1998)

15. Miles J. Urban traffic control meets Intelligent Transportation System. "Traffic technology international". Annual Review, p.p. 44-48, (1998) 